\title{
Subchronic vortioxetine treatment -but not escitalopram- enhances pyramidal neuron activity in the rat prefrontal cortex
}

\author{
Abbreviate title Subchronic vortioxetine enhances cortical activity \\ Maurizio S. Riga $\mathrm{PhD}^{1,2,3}$, Vicent Teruel-Martí $\mathrm{PhD}^{4}$, Connie Sánchez $\mathrm{PhD}^{5}$, Pau Celada $\mathrm{PhD}^{1,2,3^{*}}$, \\ Francesc Artigas $\mathrm{PhD}^{1,2,3^{*}}$ \\ ${ }^{1}$ Department of Neurochemistry and Neuropharmacology, Institut d'Investigacions Biomèdiques \\ de Barcelona, CSIC-IDIBAPS \\ ${ }^{2}$ CIBERSAM (Centro de Investigación Biomédica en Red de Salud Mental) \\ ${ }^{3}$ Institut d'Investigacions Biomèdiques August Pi i Sunyer (IDIBAPS) \\ ${ }^{4}$ Department of Human Anatomy and Embriology, Faculty of Medicine and Odontology, University \\ of Valencia, Spain \\ ${ }^{5}$ Lundbeck A/S Valby, Denmark
}

*The last two authors contributed equally to the study

Corresponding author: Francesc Artigas, PhD; Dept. of Neurochemistry and Neuropharmacology, IIBB-CSIC (IDIBAPS), Rosselló, 161, $6^{\text {th }}$ floor, 08036 Barcelona, Spain. Phone: +3493-363 8314; Fax: +3493-363 8301; e-mail: francesc.artigas@iibb.csic.es

Number of pages: 28

Number of tables: 2

Number of figures: 4

Number of words: abstract: 250 words; introduction: 483 words; discussion: 1786 words Full manuscript: 4385 words (abstract excluded) 
Highlights

- Unlike escitalopram, subchronic vortioxetine enhances PFC neuronal activity in rats

- This effect occurs at clinically-relevant oral doses of vortioxetine

- Vortioxetine increases neuronal discharge in prelimbic and infralimbic cortices

- Effects in 5-HT-depleted rats suggest a non-canonical interaction with 5-HT $-\mathrm{R}$

- These effects may underlie pro-cognitive and antidepressant actions of vortioxetine 


\section{Abstract}

Vortioxetine (VOR) is a multimodal antidepressant drug. VOR is a $5-H T_{3}-\mathrm{R}, 5-H T_{7}-\mathrm{R}$ and $5-H T_{1 D}-\mathrm{R}$ antagonist, 5- $\mathrm{HT}_{1 \mathrm{~B}}-\mathrm{R}$ partial agonist, 5- $\mathrm{HT}_{1 \mathrm{~A}}-\mathrm{R}$ agonist, and serotonin transporter (SERT) inhibitor. VOR shows pro-cognitive activity in animal models and beneficial effects on cognitive dysfunction in major depressive patients. Here we compared the effects of 14-day treatments with VOR and escitalopram (ESC, selective serotonin reuptake inhibitor) on neuronal activity in the medial prefrontal cortex (mPFC). Ten groups of rats (5 standard, 5 depleted of 5 -HT with $p$ chlorophenylalanine -pCPA-, used as model of cognitive impairment) were fed with control food or with two doses of VOR-containing food. Four groups were implanted with minipumps delivering vehicle or ESC $10 \mathrm{mg} / \mathrm{kg}$.day s.c. The two VOR doses enable occupation by VOR of SERT+5-HT $-\mathrm{R}$ and all targets, respectively, and correspond to SERT occupancies in patients treated with 5 and 20 VOR $\mathrm{mg} /$ day, respectively. Putative pyramidal neurons $(n=985)$ were recorded extracellularly in the MPFC of anesthetized rats.

Sub-chronic VOR administration (but not ESC) significantly increased neuronal discharge in standard and 5-HT-depleted conditions, with a greater effect of the low VOR dose in standard rats. VOR increased neuronal discharge in infralimbic (IL) and prelimbic (PrL) cortices. Hence, oral VOR doses evoking SERT occupancies similar to those in treated patients increase MPFC neuronal discharge. The effect in 5-HT-depleted rats cannot be explained by an antagonist action of VOR at $5-\mathrm{HT}_{3}-\mathrm{R}$ and suggests a non-canonical interaction of VOR with $5-\mathrm{HT}_{3}-\mathrm{R}$. These effects may underlie the superior pro-cognitive efficacy of VOR compared with SSRIs in animal models.

Keywords: 5-hydroxytryptamine (serotonin); $5-\mathrm{HT}_{3}$ receptors; antidepressants; medial prefrontal cortex; pyramidal neurons. 


\section{Introduction}

Vortioxetine (VOR) is a drug for the treatment of major depressive disorder (MDD) (Alvarez et al., 2012; Sanchez et al., 2015) that shows pro-cognitive efficacy in animal models (Sanchez et al., 2015; Wallace at al., 2014; Westrich et al., 2015) and improves aspects of cognitive dysfunction in MDD patients (Al-Sukhni et al., 2015; Katona et al., 2012; Mclntyre et al., 2014; 2015; Mahableshwarkar et al., 2015a, 2015b; Rosenblat et al., 2015). VOR is a 5-HT, $5-\mathrm{HT}_{7}$ and $5-\mathrm{HT}_{1 \mathrm{D}}$ receptor antagonist, $5-\mathrm{HT}_{1 \mathrm{~B}}$ receptor partial agonist, 5- $\mathrm{HT}_{1 \mathrm{~A}}$ receptor agonist, and inhibitor of the serotonin (5-HT) transporter (SERT) (Mork et al., 2012; Sanchez et al., 2015). Analyses of target occupancies in rodent brain and SERT occupancy data from human PET studies support a dosedependent occupancy of all these targets at clinical doses of vortioxetine (Sanchez et al., 2015).

VOR shows high affinity (3.7 nM) for $5-\mathrm{HT}_{3}-\mathrm{R}$ (Mørk et al., 2012). 5- $\mathrm{HT}_{3}-\mathrm{Rs}$ are ion channels present in a subpopulation of cortical and hippocampal GABAergic interneurons located in the upper layers (Lee et al., 2010; Morales and Bloom, 1997; Puig et al., 2004). 5- $\mathrm{HT}_{3}-\mathrm{R}$ physiological activation by endogenous 5-HT markedly excites a subpopulation of PFC GABA interneurons (Puig et al., 2004).

VOR administration was shown to increase extracellular concentrations of monoamines in the forebrain to a greater extent than escitalopram (ESC, selective serotonin uptake inhibitor -SSRI-) (Perhrson et al., 2013; Riga et al., 2016), likely as a result of reducing the efficacy of local and distal negative feed-back mechanisms on monoamine systems. Furthermore, co-administration of an SSRI and a $5-\mathrm{HT}_{3}-\mathrm{R}$ antagonist was shown to increase extracellular concentrations of $5-\mathrm{HT}$ in $\mathrm{mPFC}$ and hippocampus to higher levels than the SSRI alone (Mork et al., 2012; Riga et al., 2016). Moreover, acute VOR administration (but not ESC) dose-dependently was shown to enhance the discharge rate of midbrain-projecting pyramidal neurons in mPFC through a $5-\mathrm{HT}_{3}-\mathrm{R}$-dependent mechanism (Riga et al. 2016). Given the control of midbrain serotonergic neurons by the mPFC (Celada et al., 2001) this effect may translate into a greater 5-HT neuronal activity, as observed after VOR administration (Bétry et al., 2013).

Given the action of VOR (but not ESC) on cognitive function in rodents, we examined the effect of subchronic VOR and ESC administration on neuronal discharge in the MPFC of rats in standard 
conditions (drug naive) and in rats depleted of $5-\mathrm{HT}$ with the 5-HT synthesis inhibitor $p$ chlorophenylalanine $(p C P A)$. This agent induces a cognitive deficit in rodents which is partially or totally reversed by VOR (du Jardin et al., 2014; Wallace et al., 2014). Likewise, in order to relate the effects of the present study with those in treated patients, VOR was administered in the food, at two doses that result in occupation at SERT + 5- $\mathrm{HT}_{3}-\mathrm{R}$ and all targets, respectively (Alan Pehrson, unpublished observations), and producing a SERT occupancy equivalent to that in patients treated with $5 \mathrm{mg} /$ day and $20 \mathrm{mg} /$ day VOR, respectively (Sanchez et al. 2015).

\section{Material and methods}

\subsection{Animals}

Male albino Wistar rats (175-200 g at the beginning of the treatment period) were used (Charles River, France). Animal care followed the European Union regulations (directive 2010/63 of 22 September 2010) and was approved by the Institutional Animal Care and Use Committee.

\subsection{Drugs and treatments}

Vortioxetine (VOR) hydrobromide and escitalopram oxalate (ESC) were provided by $\mathrm{H}$. Lundbeck A/S. 4-chloro-DL-phenylalanine-methylester hydrochloride ( $p C P A)$ was from Sigma-Aldrich. VOR was administered p.o. in the food at doses of $0.26 \mathrm{~g}$ VOR/ $/ \mathrm{kg}$ chow and $1.8 \mathrm{~g}$ VOR $/ \mathrm{kg}$ chow. These doses evoke SERT occupancies in the rat (from $40-50 \%$ to $80-90 \%$, respectively) similar to those achieved in patients treated with the clinical doses of 5 and $20 \mathrm{mg} /$ day VOR (Leiser et al., 2015; Wallace et al., 2014). From 5 days before starting drug treatments, the regular rat chow was switched to Purina 5001 Rodent chow (control food), which had the same nutritional content as in the VOR-enriched chow (Leiser et al., 2015; Wallace et al., 2014). Animals were fed ad libitum.

ESC was administered subcutaneously (s.c.) via osmotic minipump (Alzet, model M2L2) at the dose of $10 \mathrm{mg} / \mathrm{kg}$.day (oxalate salt, corresponding to $7.5 \mathrm{mg} / \mathrm{kg}$ free base). Osmotic minipumps were implanted under anaesthesia (100 mg/kg Ketamine $+10 \mathrm{mg} / \mathrm{kg}$ Xylazine given i.p.). An analgesic 
(Buprenorfine: $0.5 \mathrm{mg} / \mathrm{kg}$ p.o every $12 \mathrm{~h}$ ) and a prophylactic antibiotic (Enofloxacina $7.5 \mathrm{mg} / \mathrm{kg}$ s.c.) were given during 2-3 consecutive days after surgery.

At the beginning of treatments (day 1), animals were single-housed and randomly assigned to one of the ten following experimental groups: 5 groups of standard rats treated with: 1) control food, 2) VOR-enriched food at low dose, 3) VOR-enriched food at high dose, 4) vehicle minipumps and 5) ESC minipumps, and 5 groups of $p C P A$-treated rats treated with the same treatments (groups 610). Treatments lasted two consecutive weeks (from day 1 to day 14). In the 5-HT depleted groups, the irreversible inhibitor of tryptophan hydroxylase $p$ CPA $(86 \mathrm{mg} / \mathrm{kg}$ free base, s.c.) was administrated daily during 4 consecutive days (from day 11 to day 14 ) in order to induce cognitive impairment through inhibition of 5-HT synthesis (du Jardin et al., 2014; Jensen et al., 2014; Wallace et al., 2014). Neuronal recordings were performed in the mPFC $24 \mathrm{~h}$ after the last $p$ CPA injection (day 15).

\subsection{Electrophysiological recordings}

Single unit extracellular recordings were performed with glass micropipettes at day 15 in chloral hydrate anesthetized rats (induction: $400 \mathrm{mg} / \mathrm{kg}$ i.p.; maintenance: $50-70 \mathrm{mg} / \mathrm{kg} / \mathrm{h}$ i.p. using a perfusion pump), as previously described (Lladó-Pelfort et al., 2012; Riga et al., 2014, 2016). Putative pyramidal neurons in the mPFC were recorded during descending tracks performed at $\mathrm{AP}+3.2$ to $3.4, \mathrm{~L}-0.7$ from bregma; DV -1.5 to $-4.8 \mathrm{~mm}$ from brain surface (Paxinos and Watson, 2005). Once a spontaneously active neuron was detected at given AP and L coordinates, its discharge was recorded for at least $5 \mathrm{~min}$. Then, the glass electrode was descended until a new spontaneously active neuron was detected and recorded. Individual firing rates were quantified by averaging the values of the last 2 min of each recording period. Typically, 1-4 tracks at different AP coordinates were performed during a 3-4 $\mathrm{h}$ recording period. Recordings were made between 10 a.m. and 4 p.m. DV coordinates of all recorded neurons were used to identify their location in prelimbic (PrL) and infralimbic (IL) subdivisions of the MPFC.

Single putative pyramidal neurons were selected on-line using standard criteria according with its long depolarization phase of the action potential and low symmetry (Lladó-Pelfort et al., 2012). In order to avoid a potential contribution of fast spiking interneurons (FSI) to the data, we performed a second off-line analysis, using built-in and self-developed MATLAB routines. The identification of 
potential FSI was performed using the following characteristics of action potentials (average of spikes from $200 \mathrm{~s}$ in basal conditions): 1) duration of the depolarization phase (depolarization width, ms), 2) duration of the hyperpolarization phase (hyperpolarization width, ms) and 3) symmetry (ratio between depolarization (a) and hyperpolarization peaks (b); Fig. 1). Using these variables, neuronal clusters were made and compared with a cluster of FSI $(n=17)$ previously recorded in the same setting (Lladó-Pelfort et al., 2012). FSI showed the following characteristics: depolarization phase width: $0.30 \pm 0.01(S D=0.06) \mathrm{ms}$; hyperpolarization phase width: $0.77 \pm 0.07$ $(S D=0.29)$ and symmetry $1.20 \pm 0.14(S D=0.56)$. Neurons meeting at least two of the following criteria: depolarization width $>0.36$ (mean+SD of $\mathrm{FSI}$; ms); hyperpolarization width $>1.08$ (mean+SD of FSI; ms); symmetry $<0.64$ or $>1.76$ (mean \pm SD of FSI) were considered putative pyramidal neurons. A total of 985 neurons were included in statistical analyses. Table 1 shows the average number of neurons included from each experimental group.

\subsection{Histology}

At the end of the recording period, animals were euthanized by an anesthetic overdose. A piece of the mPFC ( $-30-100 \mathrm{mg})$ was dissected out, weighed and frozen at -80 ㅇ C for subsequent analysis of the tissue 5-HT concentration, performed by high performance liquid chromatography (HPLC) of PFC homogenates, as described in Adell et al. (1989).

\subsection{Data and statistical analysis}

Pyramidal discharge was quantified by averaging the values of the last 2 min periods of each neuronal recording $(5 \mathrm{~min})$. Firing rate data are given as spikes/s.

Tissue 5 -HT concentrations in control and $p$ CPA-depleted rats are given as $\mathrm{fmol} / \mathrm{mg}$ tissue.

Data are expressed as mean \pm SEM. Statistical analysis was performed using Student's $t$ - test or two-way ANOVA (weight, pre-treatment, treatment or MPFC area as main factors) followed by post-hoc analysis using Duncan's test, as appropriate. To examine drug effects on neuronal discharge, we carried out two different analyses, using all individual neurons recorded $(n=985)$ and a single average value per rat $(n=50)$, as stated in Results. The second statistical analysis was 
more stringent and was used to confirm the analysis using all recorded neurons. Statistical significance has been set at the $95 \%$ confidence level (two tailed).

\section{Results}

\subsection{Effects of pharmacological treatments and implantation of subcutaneous minipumps on rat weight gain}

To assess whether the pharmacological treatments used ( $p C P A, V O R, E S C$ ) and/or the implantation of subcutaneous minipumps alter food intake in rats, we compared the weight gain (weight at day 15 - weight at day 1, in g) considering all experimental groups (10 groups, 5 rats per group) (Table 2). Overall, $p C P A$ pre-treatment altered rat weight gain, yet without significant differences between treatments. Hence, two-way ANOVA revealed a significant effect of pre-treatment $(F(1,40)=11.64 ; p<0.002)$, with no significant effect of the treatment $(F(4,40)=1.66 ; p=0.1792)$ nor pre-treatment $x$ treatment interaction $(F(4,40)=2.40 ; p=0.0658)$. The lower weight gain was seen in 5-HT-depleted rats bearing ESC minipumps ( $p<0.05$ vs control food in pCPA pre-treated rats and p<0.002 vs ESC minipumps in standard rats; post-hoc test). No significant differences emerged between drug treatments and their respective controls (low and high VOR vs control food; ESC vs vehicle controls) for any of the pre-treatments (Table 2).

\subsection{Characterization of putative pyramidal neurons in MPFC}

Putative pyramidal neurons were identified by comparing their action potential characteristics with those of a group of fast-spiking GABAergic interneurons (FSI) previously recorded in our laboratory (Lladó-Pelfort et al., 2012). Putative pyramidal neurons showed higher depolarization and hyperpolarization widths than FSI (depolarization width: $0.56 \pm 0.01$ ms vs $0.30 \pm 0.01$ ms; hyperpolarization width: $1.21 \pm 0.01 \mathrm{~ms}$ vs $0.77 \pm 0.07 \mathrm{~ms})$ and lower symmetry than FSI $(2.32 \pm 0.04$ vs $1.20 \pm 0.14, \mathrm{n}=985$ and $\mathrm{n}=17$ for putative pyramidal neurons and FSI, respectively). Despite some 
overlap in one or other variable, both neuronal subsets were grouped into 2 clearly different clusters (blue and red points for putative pyramidal neurons and FSI, respectively; Fig. 1).

\subsection{Effects of VOR and ESC on putative pyramidal neurons' activity in MPFC in standard and pCPA-treated rats}

The magnitude of $5-\mathrm{HT}$ depletion induced by pCPA in the PFC was $94 \%$ ( $804 \pm 74 v s .48 \pm 4 \mathrm{fmol} / \mathrm{mg}$ in control and $p$ CPA-treated rats, respectively; $\mathrm{n}=25$ each; $\mathrm{p}<0.00001)$ similar to that found in recent studies (du Jardin et al., 2014; Jensen et al., 2014).

Sub-chronic administration of low and high oral doses of VOR enhanced the discharge of the recorded neurons in standard and $p$ CPA-treated rats (standard rats: $0.9 \pm 0.1,2.1 \pm 0.2$ and $1.3 \pm 0.1$ spikes/s in controls, low dose VOR and high dose VOR, respectively; $p$ CPA-treated rats: 0.9 \pm 0.1 , $2.1 \pm 0.2$ and $1.8 \pm 0.2$ spikes/s, in controls, low dose VOR and high dose VOR, respectively; $n=83-120$ neurons/treatment). On the contrary, sub-chronic ESC treatment did not affect the firing rate of mPFC pyramidal neurons neither in standard nor in $p C P A$-treated rats (standard rats: from $0.8 \pm 0.1$ to $0.6 \pm 0.1$ spikes/s; $p$ CPA-treated rats: from $0.8 \pm 0.1$ to $0.8 \pm 0.1$ spikes/s, for VEH and ESC minipumps, respectively; $n=90-108$ neurons/treatment). Fig. 2 shows representative examples of the recorded neurons in each experimental group.

Two-way ANOVA revealed a significant effect of treatment on neuronal discharge $(F(4,975)=39.99$; $p<0.00001 ; n=985)$, and no significant effect of pre-treatment $(F(1,975)=3.39 ; p=0.659)$ and pretreatment $x$ treatment interaction $(F(4,975)=1.22 ; p=0.3011)$. Fig. 3A shows the results of post-hoc tests of VOR (all doses) vs. control food-treated rats (standard and $p$ CPA pre-treatment groups) and of high VOR in standard vs. pCPA-pretreated rats.

A more stringent statistical analysis was performed, by calculating the mean discharge value per each rat, thus reducing dramatically degrees of freedom (from $n=985$ to $n=50$ ). Two-way ANOVA of this data set yielded essentially the same result, with a significant effect of treatment $(F(4,40)=28.49 ; p<0.00001 ; n=50)$, no significant effect of the pre-treatment $(F(1,40)=2.99$; $p=0.0916)$ and pre-treatment $x$ treatment interaction $(F(4,40)=0.90 ; p=0.4727)$. Post-hoc analyses showed similar significant differences between groups as those found with all individual neuronal data (Fig. 3B). 
Individual neuronal data plotted in a linear Y-scale (Fig. 3C) did not allow determination of whether the significant increase of discharge produced by VOR was a general effect or if it was due to a selective action on neurons with a very high discharge, which would then increase the mean value of the group. However, when the same data was plotted in a log scale (Fig. 3D), the whole set of neuronal discharges was increased, allowing exclusion of the above possibility.

\subsection{Differential effects of VOR on Prelimbic (PrL) and Infralimbic (IL) MPFC subdivisions}

Given the increasing evidence that PrL and IL areas of the mPFC play a different role in the pathophysiology of major depression and possibly in its treatment (see Discussion), the data from all recorded neurons were split into two subpopulations according to their DV coordinate (PrL: -1.5 to -3.0 ; IL: -3.4 to -4.8 ; in $\mathrm{mm}$ from brain surface), excluding those in the border between both subdivisions (e.g., from -3.0 to $-3.4 \mathrm{~mm}$ ). In standard rats, two-way ANOVA revealed a significant effect of treatment $(F(4,450)=23.84 ; p<0.00001, n=460)$, no significant effect of area $(F(1,450)=0.63 ; p=0.4289)$ and significant area $x$ treatment interaction $(F(4,450)=2.42 ; p<0.05) . A$ significant post-hoc difference was observed between the effect of low-dose VOR in PrL and IL, with a higher increase of the discharge rate in IL in standard rats (IL: $0.7 \pm 0.1$ and 2.6 \pm 0.4 ; PrL: 1.0 \pm 0.1 and $1.9 \pm 0.2 \mathrm{spikes} / \mathrm{s}$, in control and low VOR dose rats, respectively) (Fig. 4B). In pCPAtreated rats, two-way ANOVA revealed a significant effect of treatment $(F(4,403)=13.25$; $p<0.00001, n=413)$, area $(F(1,403)=5.29 ; p<0.03)$ but not of area $x$ treatment interaction $(F(4,403)=1.53 ; p=0.1914)$. Post-hoc analysis revealed a significant increase in discharge in IL (from $1.2 \pm 0.2$ to $2.4 \pm 0.5$ spikes/s, for control and high VOR dose, respectively), but not in PrL, in rats treated with the high VOR dose (Fig. 4C). Interestingly, the differences in neuronal discharge between doses observed in IL of standard rats disappeared in the IL of $p$ CPA-treated rats. 


\section{Discussion}

The present study shows that subchronic VOR treatment (but not ESC, given for the same time period at a dose that fully blocks SERT) increased the discharge of putative pyramidal neurons in rat mPFC. The oral VOR doses were chosen to mimic in the rat the levels of SERT occupancy achieved in depressed patients treated by a low and high clinical dose of VOR ( 5 and $20 \mathrm{mg} / \mathrm{day}$, respectively). Previous studies have shown that the two oral doses result in a SERT occupancy in rat brain of approximately. $52.6 \pm 2.2 \%$ and $98.2 \pm 0.2 \%$ (Pehrson et al., 2014). According to the receptor occupancy data by vortioxetine (reviewed in Sanchez et al., 2015), this corresponds to a full occupancy of $5-\mathrm{HT}_{3}-\mathrm{R}$ at the lower dose plus a partial occupancy of $5-\mathrm{HT}_{1 \mathrm{~B}}-\mathrm{R}, 5-\mathrm{HT}_{1 \mathrm{~A}}-\mathrm{R}$ and $5-$ $\mathrm{HT}_{7}-\mathrm{R}$ at the higher dose. The observed effects are, therefore, hypothesized to be representative of effects of clinical doses, with the obvious limitations of species differences.

The increased discharge was observed in a large number of neurons per treatment group (from 85 to 120 ) and was very robust, since statistical analyses carried out with a single -average- value of neuronal discharge per rat (i.e., $n=5$ per group) revealed the same significant differences as analyses performed with the data from all recorded neurons. The large data deviation is unlikely to be caused by methodological reasons (chloral hydrate was continuously delivered by an infusion pump) and may reflect the diverse populations of pyramidal neurons recorded, in different cortical layers and with different inputs. The increase in pyramidal discharge was observed with low and high doses of VOR and in the two MPFC subdivisions, PrL and IL, although some differences between groups and treatments were noted. Likewise, VOR increased neuronal discharge in rats depleted of 5-HT with $p$ CPA, which was used as a model of cognitive deficits (du Jardin et al., 2014; Wallace et al., 2014).

The increased discharge of putative pyramidal neurons evoked by both VOR doses is in agreement with previous observations showing that cumulative i.v. doses of VOR dose-dependently increased the firing rate of midbrain-projecting pyramidal neurons in layer $V$ of the mPFC (Riga et al., 2016). This effect is mediated by $5-\mathrm{HT}_{3}-\mathrm{R}$ blockade since it was prevented by the administration of the 5$\mathrm{HT}_{3}-\mathrm{R}$ agonist SR57227A and was mimicked by the $5-\mathrm{HT}_{3}-\mathrm{R}$ antagonist ondansetron and by ESC and ondansetron combinations (Riga et al., 2016). Although we did not directly demonstrate the involvement of $5-\mathrm{HT}_{3}-\mathrm{R}$ in the subchronic VOR effect, we assume it based on the acute 
experiments and on the receptor occupancy data produced by the low and high oral VOR doses. The cellular basis of this effect is the blockade of $5-\mathrm{HT}_{3}-\mathrm{R}$ in a subpopulation of GABAergic interneurons located in upper cortical layers (Lee et al., 2010; Puig et al., 2004; Schweimer et al., 2016) an effect resulting in a reduction of $G_{A B A}-R$-mediated inputs onto pyramidal neurons and their subsequent disinhibition. In our previous study (Riga et al., 2016), we identified pyramidal neurons by antidromic stimulation from the midbrain, a technique that could not be applied here given the large number of neurons recorded. Therefore, we cannot exclude that the neuronal population included in the analyses contains a certain proportion of GABAergic interneurons, with discharge characteristics similar to that of pyramidal neurons. However, this proportion should be very low, in view of the following: 1) all GABAergic interneurons represent $15-20 \%$ of all cortical neurons, 2) putative FSI, which are mainly located in deep layers, were excluded from analyses, as described above, and 3) $5-\mathrm{HT}_{3}-\mathrm{R}$-expressing interneurons are located in layers I-III, whereas tracks aimed at deep layers. Moreover, VOR reduces the discharge of the latter interneurons (Schweimer et al., 2016), whereas a general enhancing effect of VOR was observed on neuronal discharge.

In agreement with these acute dosing experiments, subchronic VOR treatment increased neuronal discharge in standard rats. It also produced a similar enhancement in pCPA-treated rats, an observation difficult to reconcile with the antagonist character of VOR at $5-\mathrm{HT}_{3}-\mathrm{R}$ (see below for extended discussion on this point). Interestingly, Wallace et al (2014) reported that VOR improved the deficit in reversal learning induced by $P C P A$ in rats. Although this effect was interpreted in terms of the partial agonist activity of VOR at $5-\mathrm{HT}_{1 \mathrm{~A}}-\mathrm{R}$ and $5-\mathrm{HT}_{1 \mathrm{~B}}-\mathrm{R}$, the present results allow an alternative explanation, as follows. Primate studies have shown that the neurobiological substrate of short-term -or working- memory (an essential component of executive functions and a necessary step in long-term memory) is the emergence and maintenance of patterns of persistent neuronal activity in the dorsolateral PFC (equivalent to the PrL PFC in rodents). Hence, in primate experiments using visual working memory, the animals must remember the position of a visual stimulus on a screen during a delay period in the absence of the stimulus (Curtis and Esposito, 2003; Fuster and Alexander, 1971; Miller and Cohen, 2001; Wang et al., 2015). The moderate increase of neuronal discharge induced by VOR in PrL PFC may facilitate the maintenance of these activity patterns associated to short-term memory and therefore contribute to its pro-cognitive effects. In support of this view, $5-\mathrm{HT}_{3}-\mathrm{R}$ agonists impair short-term and long-term memory in rats (Meneses, 2007) and the $5-\mathrm{HT}_{3}-\mathrm{R}$ antagonists ondansetron and tropisetron improve memory 
consolidation (Meneses 2003). On the other hand, the effect of VOR on neuronal discharge may counteract the fall in working memory induced by psychological stress, associated with a reduced dorsolateral PFC activity, (Qin et al., 2009). However, alternative explanations may be equally valid, since psychotomimetic drugs produce a very large increase of pyramidal neurons discharge in mPFC (e.g., Kargieman et al., 2007) and cognitive enhancers may act via different neuronal mechanisms (Husain and Mehta, 2011). In particular, the activation of $5-\mathrm{HT}_{1 \mathrm{~A}}-\mathrm{R}$ by VOR may play an important role. 5- $\mathrm{HT}_{1 \mathrm{~A}}-\mathrm{R}$ agonists increase acetylcholine release (Izumi et al., 1994; Fujii et al., 1997; Koyama et al., 1999), an effect that may explain the VOR-induced elevation of acetylcholine in acute microdialysis experiments (Mork et al., 2013). However, using the subchronic oral dosing regimen of the present study VOR failed to produce a sustained extracellular elevation of acetylcholine (Pehrson et al., 2016).

The similar effects of subchronic VOR treatment on neuronal discharge in standard and 5-HTdepleted rats suggest a similar antagonist action of VOR in both pre-treatment groups. However, an antagonist action is difficult to explain in rats with a very large degree (94\%) of depletion of 5HT stores, as produced by this treatment regime with $p C P A$. This raises the possibility that VOR interacts in a non-canonical way with $5-\mathrm{HT}_{3}-\mathrm{R}$. Interestingly, the $5-\mathrm{HT}_{3}-\mathrm{R}$ antagonist ondansetron can antagonize peristaltic movements in reserpinized guinea pigs (Sia et al., 2013). Although in different species and systems, both observations support the view that $5-\mathrm{HT}_{3}-\mathrm{R}$ blockade may evoke cellular/molecular actions independent of the presence of 5-HT.

VOR was characterized in vitro as a high affinity antagonist at rat and human $5-\mathrm{HT}_{3 \mathrm{~A}}-\mathrm{R}$ (BangAndersen et al., 2011; Sánchez et al., 2012). However, 5- $\mathrm{HT}_{3 \mathrm{~B}}-\mathrm{R}$ subunits are largely co-expressed with $5-\mathrm{HT}_{3 \mathrm{~A}}-\mathrm{R}$ in rodent brain (Doucet et al., 2007) and their association to 5-HT $3 \mathrm{~A}^{-} \mathrm{R}$ subunits modifies channel properties, including the duration of the agonist response as well as agonist and antagonist affinities (Dubin et al., 1999). More recently, it has been shown that the $5-\mathrm{HT}_{3 \mathrm{~B}}-\mathrm{R}$ subunit confers spontaneous channel opening and alters ligand interaction with the receptor. Hence, the 5-HT analog 5-hydroxyindole acts as a partial agonist at 5- $\mathrm{HT}_{3 \mathrm{~A}}-\mathrm{R}$ and as an agonist or inverse agonist at 5- $\mathrm{HT}_{3 \mathrm{AB}}$ receptors ( $\mathrm{Hu}, 2015 ; \mathrm{Hu}$ and Peoples, 2008). Likewise, the interaction of various $5-\mathrm{HT}_{3}-\mathrm{R}$ ligands with palonosetron, a $5-\mathrm{HT}_{3}-\mathrm{R}$ antagonist with slow dissociation kinetics, depends on the subunit composition (5- $\mathrm{HT}_{3 \mathrm{~A}}$ or $5-\mathrm{HT}_{3 \mathrm{AB}}$ ) (Lumuis and Thompson, 2013). Overall, these observations raise the possibility that VOR -and possibly other $5-\mathrm{HT}_{3}-\mathrm{R}$ antagonists- interact with $5-\mathrm{HT}_{3}-\mathrm{R}$ in a non-canonical form, e.g., stabilizing the inactive -closed-form of the channel, 
even in the absence of 5-HT. This possibility is supported by the slow dissociation kinetics of VOR observed in in vitro electrophysiology studies in oocytes ( Kristen Fredriksen, Lundbeck; personal communication) and would require appropriate experimental testing. Hence, it would be interesting to examine whether VOR and other 5-HT3-R antagonists (e.g., ondansetron, palonosetron) increase pyramidal neurons activity after acute treatment in rats depleted of 5-HT by various means (e.g., $p$ CPA, 5,7-DHT, low tryptophan diet).

The IL and PrL subdivisions of the MPFC project to different subcortical areas (Vertes, 2004) and exert mutual inhibitory control. Hence, the optogenetic stimulation of pyramidal neurons in IL inhibited pyramidal neurons in PL (Ji and Neugebauer, 2012). Despite this, VOR was able to increase the discharge of putative pyramidal neurons in both subdivisions. The increased discharge in PrL may be involved in the pro-cognitive actions of VOR, as discussed above. On the other hand, the IL subdivision is equivalent to the ventral anterior cingulate (VACC) in primate and human brain, which plays a key role in the pathophysiology and treatment of major depression. Hence, alterations of the energy metabolism have been reported in vACC (Drevets et al., 1997; Simonewicz et al., 2004; Drevets et al., 2008) and the deep brain stimulation of Broadman area 25, in the VACC, evokes a rapid improvement of major depressive patients refractory to antidepressant treatments (Mayberg et al., 2005; Puigdemont et al., 2011). In rodents, this area also appears to play a major role in antidepressant-like treatments. Hence, local application of the non-competitive NMDA-R antagonist ketamine in IL evoked rapid and persistent antidepressantlike effects in rats, an action mimicked by the optogenetic stimulation of the same area (Fuchikami et al, 2015). Likewise, the pharmacological blockade of the astroglial glutamate transporter GLT-1 in rat IL (but not in PrL) also evoked antidepressant like effects in the forced-swim and the noveltysuppressed feeding tests (Gasull et al., 2015). Overall, these reports suggest that the increase of excitatory neurotransmission in the IL may contribute to the antidepressant effects of VOR but not ESC, in addition to the increase of forebrain monoaminergic neurotransmission (Mork et al., 2012; Riga et al., 2016).

Interestingly, the differences in neuronal discharge between doses observed in IL of standard rats disappeared in the IL of $p$ CPA-treated rats. Given the different target occupancies by low and high VOR doses (SERT + 5- $\mathrm{HT}_{3}-\mathrm{R}$ and all targets, respectively), the different effect on IL discharge in standard rats, and the similar effect in $p$ CPA-treated rats, the occupancy of non- $5-\mathrm{HT}_{3}-\mathrm{R}$ targets by 
endogenous 5-HT at high VOR doses may be responsible for the inverse relationship between VOR dose and neuronal discharge in IL.

\section{Conclusions}

In summary, the present study shows that subchronic treatment with VOR, but not ESC, increases neuronal activity in the two subdivisions of the mPFC, PrL and IL, in standard rats and in rats depleted of 5-HT with $p$ CPA. The effect in PrL may account for the pro-cognitive activity of VOR in animal models whereas that in IL may contribute to the antidepressant effects of VOR, given recent observations indicating that the increased excitatory neurotransmission in this area evokes antidepressant-like effects in rodents. The use of VOR doses resulting in target occupancies similar to those observed in patients at clinical doses suggest that the increased neuronal discharge may also occur in human brain. The use of neuroimaging techniques (e.g., positron emission tomography scan, functional magnetic resonance imaging ) for studies of these sub regions would allow the examination of vortioxetine effects on PFC activity in patients and whether they are associated to the improvement of cognitive deficits.

\section{Acknowledgements}

Supported by Lundbeck A/S and grants: SAF2015-68346-P (Spanish Ministry of Economy and Competitiveness, co-financed by European Regional Development Fund (ERDF)) and PI12/00156 (Instituto de Salud Carlos III, co-financed by European Regional Development Fund (ERDF)). Support from the Centro de Investigación Biomédica en Red de Salud Mental (CIBERSAM) and Generalitat de Catalunya Grup de Recerca Consolidat, 2014SGR798 is also acknowledged. We thank Mercedes Núñez for technical assistance.

FA and $\mathrm{PC}$ are $\mathrm{PI}$ and co-PI from a grant from Lundbeck $\mathrm{A} / \mathrm{S}$ to examine the mechanism of action of vortioxetine. FA has also received consultation fees from Lundbeck $A / S$ and is scientific advisor to Neurolixis. CS is a Lundbeck A/S employee. 


\section{References}

Adell, A., Sarna, GS., Hutson, PH., Curzon, G., 1989. An in vivo dialysis and behavioural study of the release of 5-HT by p-chloroamphetamine in reserpine-treated rats. Br J Pharmacol 97, 206- 212.

Al-Sukhn, M., Maruschak, NA., McIntyre, RS., 2015. Vortioxetine: a review of efficacy, safety and tolerability with a focus on cognitive symptoms in major depressive disorder. Expert Opin Drug Saf. 14, 1291-1304.

Alvarez, E., Perez, V., Dragheim, M., Loft, H., Artigas, F., 2012. A double-blind, randomized, placebo-controlled, active reference study of Lu AA21004 in patients with major depressive disorder. Int J Neuropsychopharmacol 15. 589-600.

Amargós-Bosch, M., Bortolozzi, A., Puig, MV., Serrats, J., Adell, A., Celada, P. et al., 2004. Coexpression and in vivo interaction of serotonin $1 \mathrm{~A}$ and serotonin2A receptors in pyramidal neurons of prefrontal cortex. Cereb Cortex. 14, 281-99.

Bang-Andersen, B., Ruhland, T., Jørgensen, M., Smith, G., Frederiksen, K., Jensen, KG., Zhong, H., Nielsen, SM., Hogg, S., Mørk, A., Stensbøl, TB., 2011. Discovery of 1-[2-(2,4dimethylphenylsulfanyl)phenyl]piperazine (Lu AA21004): a novel multimodal compound for the treatment of major depressive disorder. J Med Chem. 54, 3206-21.

Bétry, C., Pehrson, AL., Etiévant, A., Ebert, B., Sánchez, C., Haddjeri, N., 2013. The rapid recovery of 5-HT cell firing induced by the antidepressant vortioxetine involves 5-HT(3) receptor antagonism. Int J Neuropsychopharmacol. 16, 1115-27. 
Bétry, C., Etiévant, A., Pehrson, A., Sánchez, C., Haddjeri, N., 2015. Effect of the multimodal acting antidepressant vortioxetine on rat hippocampal plasticity and recognition memory. Prog Neuropsychopharmacol Biol Psychiatry. 58, 38-46.

Celada, P., Puig, MV., Casanovas, JM., Guillazo, G., Artigas, F., 2001. Control of dorsal raphe serotonergic neurons by the medial prefrontal cortex: Involvement of serotonin-1A, GABA(A), and glutamate receptors. J Neurosci. 21, 9917-29.

Curtis, CE. and D'Esposito, M., 2003. Persistent activity in the prefrontal cortex during working memory. Trends Cogn Sci. 7, 415-423.

Doucet, E., Latrémolière, A., Darmon, M., Hamon, M., Emerit, MB., 2007. Immunolabelling of the 5-HT 3B receptor subunit in the central and peripheral nervous systems in rodents. Eur J Neurosci. $26,355-66$.

Drevets, WC., Price, JL., Simpson, JR Jr., Todd, RD., Reich, T., Vannier, M., Raichle, ME. 1997. Subgenual prefrontal cortex abnormalities in mood disorders. Nature. 386, 824-7.

Drevets, WC., Savitz, J., Trimble, M., 2008. The subgenual anterior cingulate cortex in mood disorders. CNS Spectr 13, 663-81.

Dubin, AE., Huvar, R., D'Andrea, MR., Pyati, J., Zhu, JY., Joy, KC., Wilson, SJ., Galindo, JE., Glass, CA., Luo, L., Jackson, MR., Lovenberg, TW., Erlander, MG., 1999. The pharmacological and functional characteristics of the serotonin $5-\mathrm{HT}(3 \mathrm{~A})$ receptor are specifically modified by a $5-\mathrm{HT}(3 \mathrm{~B})$ receptor subunit. J Biol Chem. 274, 30799-810. 
du Jardin, KG., Jensen, JB., Sanchez, C., Pehrson, AL., 2014. Vortioxetine dose-dependently reverses 5-HT depletion-induced deficits in spatial working and object recognition memory: a potential role for $5-\mathrm{HT}_{1 \mathrm{~A}}$ receptor agonism and $5-\mathrm{HT}_{3}$ receptor antagonism. Eur Neuropsychopharmacol. 24, 160-71.

Fuchikami, M., Thomas, A., Liu, R., Wohleb, ES., Land, BB., DiLeone, RJ., Aghajanian, GK., Duman, RS., 2015. Optogenetic stimulation of infralimbic PFC reproduces ketamine's rapid and sustained antidepressant actions. Proc Natl Acad Sci U S A. 112, 8106-11.

Fujii, T., Yoshizawa, M., Nakai, K., Fujimoto, K., Suzuki, T., Kawashima, K., 1997. Demonstration of the facilitatory role of 8-OH-DPAT on cholinergic transmission in the rat hippocampus using in vivo microdialysis. Brain Res. 761, 244-9.

Fuster, JM. and Alexander, GE., 1971. Neuron activity related to short-term memory. Science. 173, 652-4.

Gasull-Camos, J., Artigas, F., Castane, A., 2015. Modulation of glutamatergic transmission in the infralimbic cortex evokes antidepressant-like effects in rats. Eur Neuropsychopharmacology 25, S127-S128.

Husain, M., Mehta, MA. 2011. Cognitive enhancement by drugs in health and disease. Trends Cogn 15, 28-36.

Hu, XQ., 2015. Auto-inhibition at a ligand-gated ion channel: a cross-talk between orthosteric and allosteric sites. Br J Pharmacol. 172, 93-105. 
Hu, XQ. and Peoples, RW., 2008. The 5-HT3B subunit confers spontaneous channel opening and altered ligand properties of the 5-HT3 receptor. J Biol Chem. 283, 6826-31.

Jensen, B., DuJardin, DK., Song, D., Budac, D., Smagin, D., Sanchez, C., Pehrson, AL., 2014. Vortioxetine, but not escitalopram or duloxetine, reverses memory impairment induced by central 5-HT depletion in rats: Evidence for direct 5-HT receptor modulation. Eur Neuropsychopharmacology 24, 148-159.

Ji, G., Neugebauer, V., 2012. Modulation of medial prefrontal cortical activity using in vivo recordings and optogenetics. Mol Brain. 8, 5-36.

Katona, C., Hansen,T., Olsen,C.K., 2012. Rarandomized, double- blind, placebo- Controlled, duloxetine-referenced, fixed-dose study comparing the efficacy and safety of LuAA21004 in elderly patients with major depressive disorder .Int.Clin.Psychopharmacol. 27, 215-223.

Koyama, T., Nakajima, Y., Fujii, T., Kawashima, K., 1999. Enhancement of cortical and hippocampal cholinergic neurotransmission through $5-\mathrm{HT} 1 \mathrm{~A}$ receptor-mediated pathways by BAY $\times 3702$ in freely moving rats. Neurosci Lett. 265, 33-6.

Izumi, J., Washizuka, M., Miura, N., Hiraga, Y., Ikeda, Y, 1994. Hippocampal serotonin 5-HT1A receptor enhances acetylcholine release in conscious rats. J Neurochem. 62, 1804-8.

Lee, S., Hjerling-Leffler, J., Zagha, E., Fishell, G., Rudy, B., 2010. The largest group of superficial neocortical GABAergic interneurons expresses ionotropic serotonin receptors. J Neurosci. 30, 16796-808 
Leiser, SC., Iglesias-Bregna, D., Westrich, L., Pehrson, AL., Sanchez, C., 2015. Differentiated effects of the multimodal antidepressant vortioxetine on sleep architecture: Part 2, pharmacological interactions in rodents suggest a role of serotonin-3 receptor antagonism. J Psychopharmacol. 29, 1092-105.

Lladó-Pelfort, L., Santana, N., Ghisi, V., Artigas, F., Celada, P., 2012. 5-HT1A receptor agonists enhance pyramidal cell firing in prefrontal cortex through a preferential action on GABA interneurons. Cereb Cortex 22, 1487-97.

Lummis, SC. and Thompson, AJ., 2013. Agonists and antagonists induce different palonosetron dissociation rates in 5- $\mathrm{HT}_{3} \mathrm{~A}$ and 5- $\mathrm{HT}_{3} \mathrm{AB}$ receptors. Neuropharmacology. 73, 241-6.

Mahableshwarkar, AR., Jacobsen, PL., Serenko, M., Chen, Y., Trivedi, MH., 2015a. A randomized, double-blind, placebo-controlled study of the efficacy and safety of 2 doses of vortioxetine in adults with major depressive disorder. J Clin Psychiatry. 76, 583-9.

Mahableshwarkar, AR., Zajecka, J., Jacobson, W., Chen, Y., Keefe, RS., 2015b. A Randomized, Placebo-Controlled, Active-Reference, Double-Blind, Flexible-Dose Study of the Efficacy of Vortioxetine on Cognitive Function in Major Depressive Disorder. Neuropsychopharmacology 40, 2025-2037.

Mayberg, HS., Lozano, AM., Voon, V., McNeely, HE., Seminowicz, D., Hamani, C. et al., 2005. Deep brain stimulation for treatment resistant depression. Neuron 45, 651-660.

McIntyre, RS., Lophaven, S., Olsen, CK., 2014. A randomized, doubleblind, placebo-controlled study of vortioxetine on cognitive function in depressed adults. Int J Neuropsychopharmacol 17, 1557-1567. 
McIntyre, RS., Xiao, HX., Syeda, K., Vinberg, M., Carvalho, AF., Mansur, RB., Maruschak, N., Cha, DS., 2015. The Prevalence, Measurement, and Treatment of the Cognitive Dimension/Domain in Major Depressive Disorder. CNS Drugs 29, 577-589.

Meneses, A., 2003. A pharmacological analysis of an associative learning task: $5-\mathrm{HT}(1)$ to $5-\mathrm{HT}(7)$ receptor subtypes function on a pavlovian/instrumental autoshaped memory. Learn Mem. 10, 363-72. Review.

Meneses, A., 2007. Stimulation of 5-HT1A, 5-HT1B, 5-HT2A/2C, 5-HT3 and 5-HT4 receptors or 5-HT uptake inhibition: short- and long-term memory. Behav Brain Res. 184, 81-90.

Miller, EK. and Cohen, JD., 2001. An integrative theory of prefrontal cortex function. Annu Rev Neurosci. 24, 167-202. Review.

Morales, M. and Bloom, FE., 1997. The 5-HT3 receptor is present in different sub populations of GABAergic neurons in the rat telencephalon. J. Neurosci. 17, 3157-3167.

Mork, A., Pehrson, A., Brennum, LT., Nielsen, SM., Zhong, H., Lassen, AB. et al., 2012. Pharmacological effects of Lu AA21004: a novel multimodal compound for the treatment of major depressive disorder. J Pharmacol Exp Ther 340, 666-675.

Mork, A., Montezinho, LP., Miller, S., Trippodi-Murphy, C., Plath, N., Li, Y., Gulinello, M., Sanchez, C., 2013. Vortioxetine (Lu AA21004), a novel multimodal antidepressant, enhances memory in rats. Pharmacol Biochem Behav. 105, 41-50.

Paxinos, G. and Watson, C., 2005. The rat brain in stereotaxic coordinates, 5th edn. San Diego: Elsevier Academic Press. 
Pehrson, AL., Cremers, T., Betry, C., van der Hart, MG., Jorgensen, L., Madsen, M. et al., 2013. Lu AA21004, a novel multimodal antidepressant, produces regionally selective increases of multiple neurotransmitters-a rat microdialysis and electrophysiology study. Eur Neuropsychopharmacol 23, 133-145.

Pehrson, AL., Waller, J., Plath, N., Sanchez, C., 2014. Vortioxetine treatment reverses cognitive impairment induced by long-term dysregulation of glutamate neurotransmission in rats. Int. J.Neuropsychopharmacol. 17, 139 (P-42-022).

Pehrson AL, Hillhouse TM, Haddjeri N, Rovera R, Porter JH, Mørk A, Smagin G, Song D, Budac D, Cajina M, Sanchez C. Task- and Treatment Length-Dependent Effects of Vortioxetine on Scopolamine-Induced Cognitive Dysfunction and Hippocampal Extracellular Acetylcholine in Rats. J Pharmacol Exp Ther. 2016 Sep;358(3):472-82. doi: 10.1124/jpet.116.233924. Epub 2016 Jul 11

Puig, MV., Santana, N., Celada, P., Mengod, G., Artigas, F., 2004. In vivo excitation of GABA interneurons in the medial prefrontal cortex through 5-HT3 receptors. Cereb Cortex 14, 13651375.

Puig, MV., Artigas, F., Celada, P., 2005. Modulation of the activity of pyramidal neurons in rat prefrontal cortex by raphe stimulation in vivo: involvement of serotonin and GABA. Cereb Cortex $15,1-14$.

Puigdemont, D., Perez-Egea, R., Portella, MJ., Molet, J., DiegoAdelino, J., Gironell, A., et al., 2011. Deep brain stimulation of the subcallosal cingulate gyrus: further evidence in treatment-resistant major depression. Int.J.Neuropsychopharmacol. 15, 1-13. 
Qin, S., Hermans, EJ., van Marle, HJ., Luo, J., Fernández, G., 2009. Acute psychological stress reduces working memory-related activity in the dorsolateral prefrontal cortex. Biol Psychiatry. 66, 25-32.

Riga, MS., Soria, G., Tudela, R., Artigas, F., Celada, P., 2014. The natural hallucinogen 5-MeO-DMT, component of Ayahuasca, disrupts cortical function in rats: reversal by antipsychotic drugs. Int J Neuropsychopharmacol 17, 1269-82.

Riga, MS., Sanchez, C., Celada, P., Artigas, F., 2016. Involvement of 5-HT3 receptors in the action of vortioxetine in rat brain: focus on glutamatergic and GABAergic neurotransmission. Neuropharmacol. 108, 73-81.

Rosenblat, JD., Kakar, R., McIntyre, RS., 2015. The cognitive effects of antidepressants in major depressive disorder: a systematic review and meta-analysis of randomized clinical trials. Int J Neuropsychopharmacol In press. DOI: 10.1093/ijnp/pyv082.

Sanchez, C., Asin, KE., Artigas, F., 2015. Vortioxetine, a novel antidepressant with multimodal activity: review of preclinical and clinical data. Pharmacol Ther. 145, 43-57.

Sanchez, C., Westrich, L., Zhong, H., Nielsen, SM., Boyle, N., Hentzer, K., Fredriksen, K., Stensbol, TB., 2012. In vitro effects of the multimodal antidepressant Lu AA21004 at human and rat 5-HT1A, 5-HT1B, 5-HT3 and 5-HT7 receptors, and 5-HT transporters Eur Neuropsychopharmacol, 22 (Suppl. 2), S245-S246.

Santana, N., Bortolozzi, A., Serrats, J., Mengod, G., Artigas, F., 2004. Expression of serotonin1A and serotonin2A receptors in pyramidal and GABAergic neurons of the rat prefrontal cortex. Cereb Cortex. 14, 1100-9. 
Schweimer, J.V, Li, Y., Sanchez, C., Sharp, T., 2016. In vivo electrophysiological evidence for the targeting of $5-\mathrm{HT} 3 \mathrm{R}$ expressing cortical interneurons by the novel multimodal antidepressant vortioxetine. SOBP abstract 2016.

Seminowicz, DA., Mayberg, HS., McIntosh, AR., Goldapple, K., Kennedy, S., Segal, Z., Rafi-Tari, S., 2004. Limbic-frontal circuitry in major depression: a path modeling metanalysis. Neuroimage. 22, 409-18.

Sia, TC., Whiting, M., Kyloh, M., Nicholas, SJ., Oliver, J., Brookes, SJ., Dinning, PG., Wattchow, DA., Spencer, NJ., 2013. 5-HT3 and 5-HT4 antagonists inhibit peristaltic contractions in guinea-pig distal colon by mechanisms independent of endogenous 5-HT. Front Neurosci. 7, 136.

Tierney, PL., Dégenètais, E., Thierry, AM., Glowinski, J., Gioanni, Y., 2004. Influence of the hippocampus on interneurons of the rat prefrontal cortex. Eur J Neurosci. 20, 514-524.

Vertes, RP., 2004. Differential projections of the infralimbic and prelimbic cortex in the rat. Synapse. 51, 32-58.

Wallace, A., Pehrson, AL., Sanchez, C., Morilak, DA., 2014. Vortioxetine restores reversal learning impaired by 5-HT depletion or chronic intermittent cold stress in rats. Int J Neuropsychopharmacol $17,1695-1706$.

Wang, L., Li, X., Hsiao, SS., Lenz, FA., Bodner, M., Zhou, YD., Fuster, JM., 2015. Differential roles of delay-period neural activity in the monkey dorsolateral prefrontal cortex in visual-haptic crossmodal working memory. Proc Natl Acad Sci U S A. 112, E214-9. 
Westrich, L., Haddjeri, N., Dkhissi-Benyahya, O., Sánchez, C., 2015. Involvement of 5-HT7 receptors in vortioxetine's modulation of circadian rhythms and episodic memory in rodents. Neuropharmacology 89, 382-90. 
Table 1. Average number of recorded neurons per rat in the 10 experimental groups ( 5 standard conditions, 5 depleted of 5 -HT with $p$ CPA; 5 rats/group)

\begin{tabular}{|c|c|c|}
\hline Groups & Standard & $p$ CPA \\
\hline Control food & 19 neurons/rat & 17 neurons/rat \\
\hline Low VOR & 23 neurons/rat & 18 neurons/rat \\
\hline High VOR & 24 neurons/rat & 18 neurons/rat \\
\hline VEH minipumps & 19 neurons/rat & 19 neurons/rat \\
\hline ESC minipumps & 18 neurons/rat & 22 neurons/rat \\
\hline All recorded neurons & 516 neurons (25 rats) & 469 neurons (25 rats) \\
\hline
\end{tabular}


Table 2. Weight gain in all experimental groups (5 rats/group).

\begin{tabular}{|c|c|c|c|c|c|}
\hline & $\begin{array}{c}\text { Control food } \\
\mathbf{( g )}\end{array}$ & $\begin{array}{c}\text { Low VOR } \\
\mathbf{( g )}\end{array}$ & $\begin{array}{c}\text { High VOR } \\
\mathbf{( g )}\end{array}$ & $\begin{array}{c}\text { VEH minipumps } \\
\mathbf{( g )}\end{array}$ & $\begin{array}{c}\text { ESC minipumps } \\
\mathbf{( g )}\end{array}$ \\
\hline Standard & $80.8 \pm 3.1$ & $89 \pm 8.2$ & $73.8 \pm 8.0$ & $85.2 \pm 4.3$ & $94.4 \pm 5.2$ \\
\hline$p C P A$ & $82.8 \pm 2.3$ & $79.4 \pm 8.1$ & $67.8 \pm 4.4$ & $68.8 \pm 2.0$ & $63.6 \pm 6.1^{* \#}$ \\
\hline
\end{tabular}

Data (g) are expressed as mean \pm SEM. * $\mathrm{p}<0.05$ versus Control food in $p$ CPA pre-treated rats; \# $\mathrm{p}<0.002$ versus ESC minipumps in standard rats. 


\section{Figure legends}

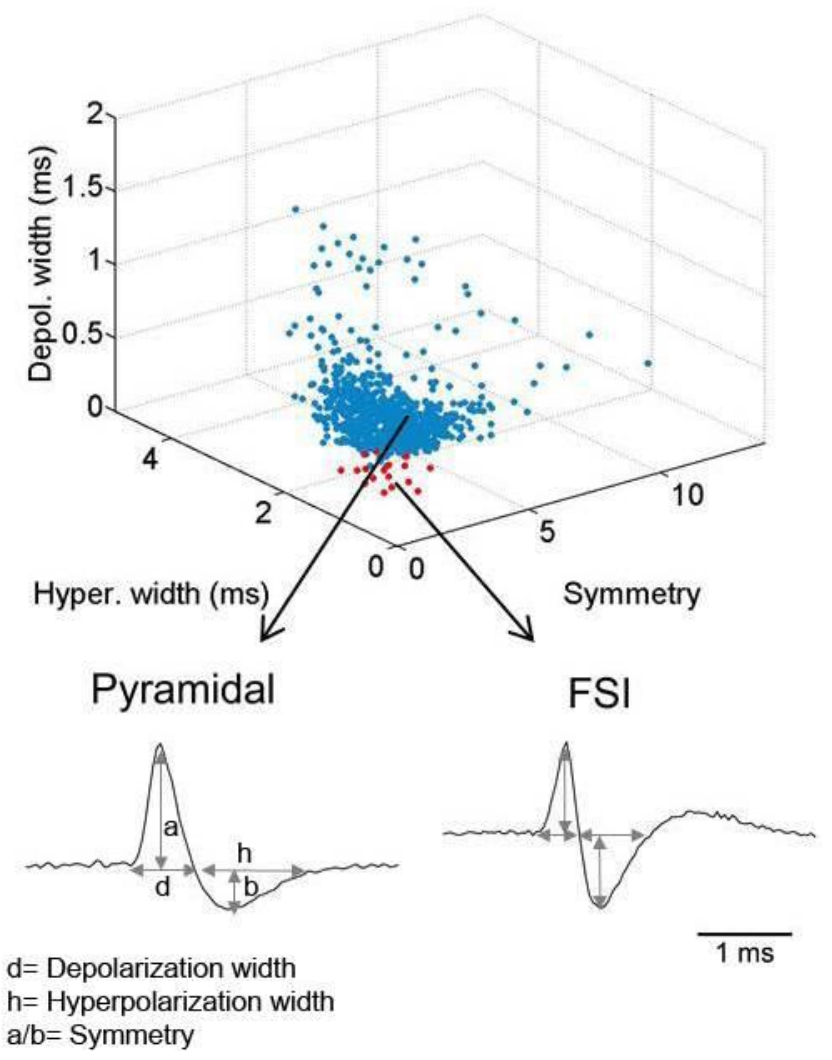

Figure 1. Characterization of putative pyramidal neurons in the mPFC. Plotting the symmetry of action potential $(\mathrm{X})$ versus the hyperpolarization width $(\mathrm{Y})$ versus the depolarization width $(\mathrm{Z})$ creates 2 separate clusters grouping putative pyramidal neurons on one side (in blue) and GABAergic fast-spiking interneurons on the other (in red). Putative pyramidal neurons show higher depolarization and hyperpolarization phases of action potential and lower symmetry ratio (> 1) compared to GABAergic FSI (Lladó-Pelfort et al., 2012). The pyramidal and GABAergic FSI action potentials shown in the figure, are obtained by averaging 10 spikes and they correspond to the plot indicated by the arrows. 


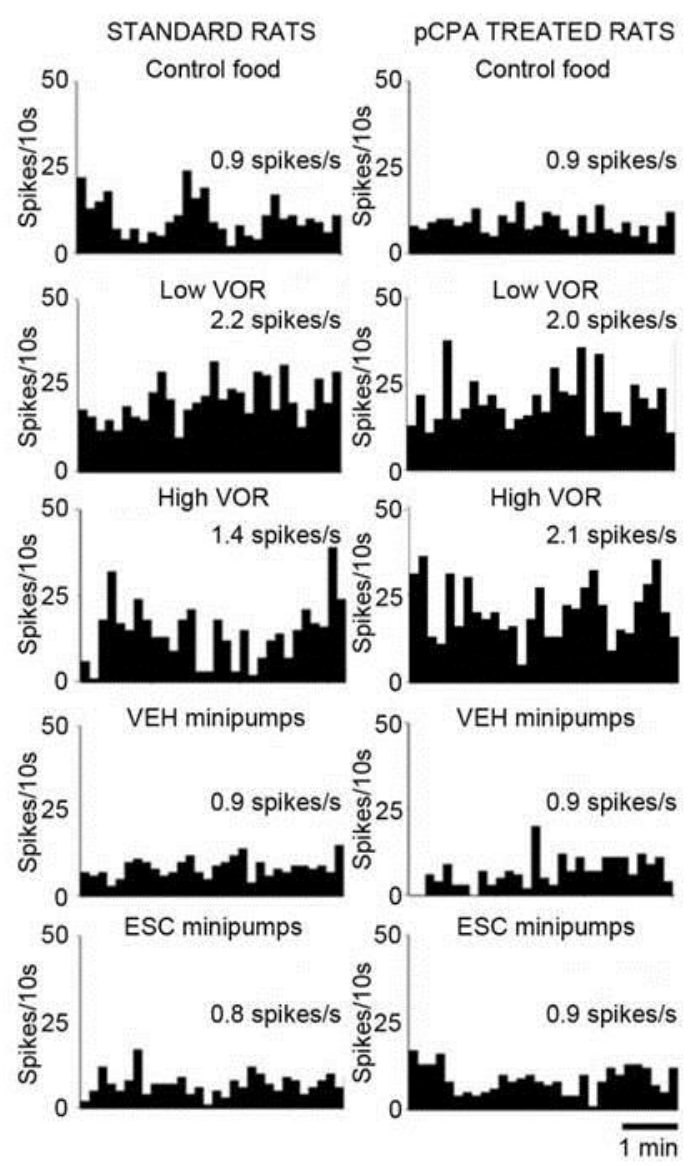

Figure 2. Effect of sub-chronic vortioxetine (VOR) and escitalopram (ESC) treatments on firing rate of putative MPFC pyramidal neurons. Representative histograms of recorded pyramidal neurons from standard and $p$ CPA-treated rats administrated with control food, low and high VOR enriched food $(0.26$ and $1.8 \mathrm{~g} / \mathrm{kg}$ of chow, respectively), vehicle (VEH) and ESC (10 mg/kg/day s.c.) filled osmotic minipumps. The firing rate (spikes/s) quantified by averaging the values of the last 2 min of each neuronal recording $(5 \mathrm{~min})$ is also shown. 
Riga et al.

A

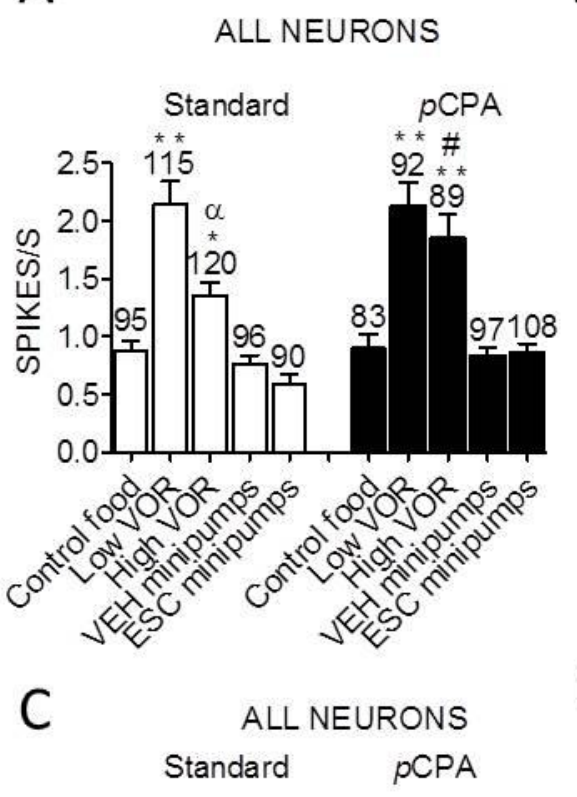

B

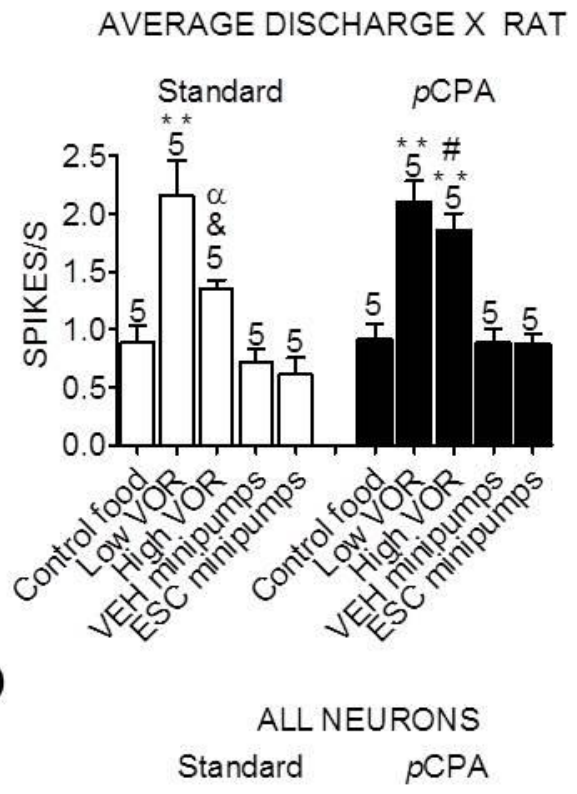

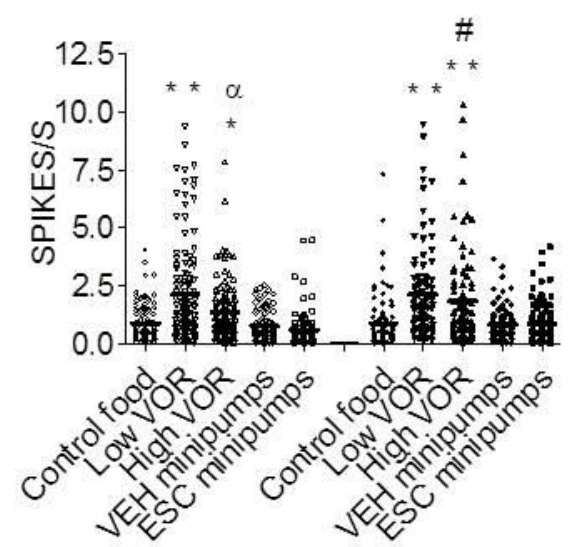

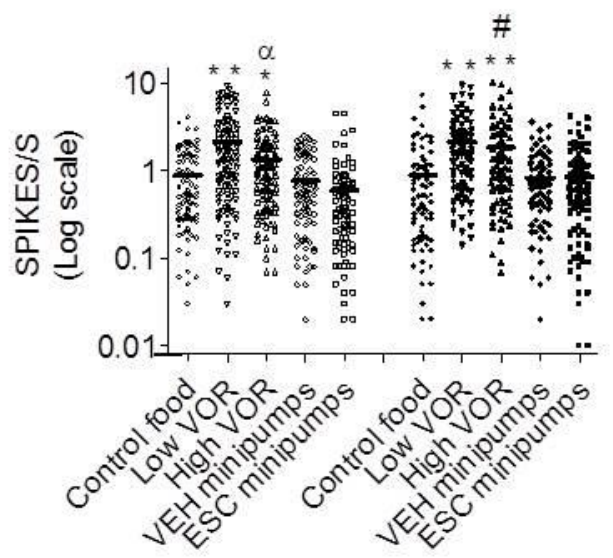

Figure 3. Effect of sub-chronic vortioxetine (VOR) and escitalopram (ESC) treatments on firing rate of putative mPFC pyramidal neurons. A and B) Bar graphs showing the mean values of all neurons recorded (A) and the mean of neuronal average discharge per rat (B) in each experimental group. The number of neurons (A) or rats (B) in each experimental group is shown above the respective bars. C and D) Plot graphs representing the individual discharge rates of all neurons recorded in linear (C) and Log 10 (D) ordinate scale to better visualize effects on high and low discharge neurons, respectively. Note that sub-chronic VOR increases the activity of high and low discharge neurons. ${ }^{*} \mathrm{p}<0.03$ and ${ }^{* *} \mathrm{p}<0.0005$ versus Control food; \# $\mathrm{p}<0.05$ versus High VOR in standard rats; $\alpha p<0.002$ versus Low VOR in standard rats; $\& p=0.056$ (marginally) versus Control food. 


\section{A}
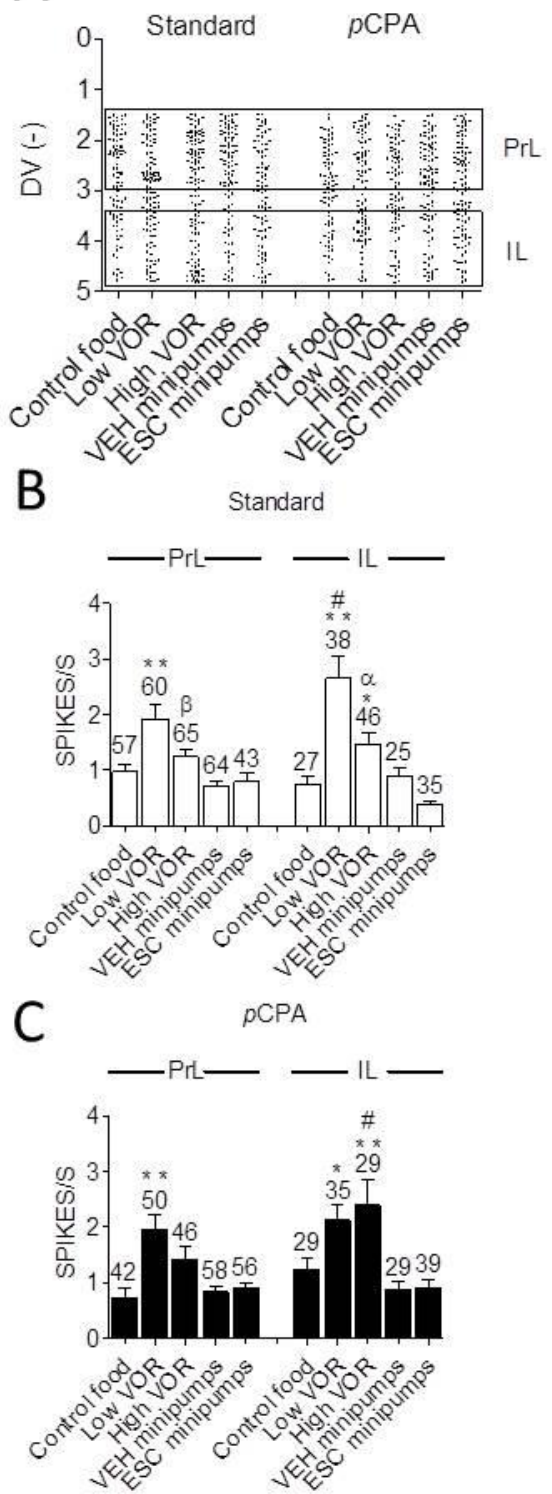

Figure 4. Effect of sub-chronic VOR and ESC treatments on firing rate of putative pyramidal neurons in rat prelimbic (PrL) and infralimbic (IL) subdivisions of the mPFC. A) Plot graph representing the dorsoventral (DV) localization of the recorded pyramidal neurons grouped for treatment. Black boxes show pyramidal neurons selected in PrL (-1.5 to -3.0) and IL (-3.4 to -4.8; in $\mathrm{mm}$ from brain surface) and used in statistical analysis B) and C) Bar graphs show the effect of sub-chronic treatments with VOR and ESC in PrL and IL subdivisions in standard B) and $p$ CPAtreated rats $\mathbf{C}$ ). The number of neurons recorded in each experimental group is shown above the respective bars. ${ }^{*} p<0.03$ and ${ }^{* *} p<0.002$ versus Control food; $\# p<0.02$ versus Low VOR in $\operatorname{PrL}$ in 
standard rats and \# $p<0.005$ versus High VOR in PrL in $p$ CPA-treated rats; $\alpha p<0.0001$ versus Low VOR in IL; $ß p<0.05$ versus Low VOR in PrL. 